\title{
Ethinylestradiol is beneficial for postmenopausal patients with heavily pre-treated metastatic breast cancer after prior aromatase inhibitor treatment: a prospective study
}

H lwase ${ }^{\star}{ }^{1}$, Y Yamamoto ${ }^{1}$, M Yamamoto-lbusuki ${ }^{1}$, K-I Murakami ${ }^{1}$, Y Okumura ${ }^{1}$, S Tomita ${ }^{1}$, T Inao ${ }^{1}$, Y Honda ${ }^{2}$, Y Omoto ${ }^{1}$ and K-I lyama ${ }^{2}$

${ }^{1}$ Department of Breast and Endocrine Surgery, Kumamoto University, 1-1-1 Honjo, Chuo-ku, Kumamoto 860-8556, Japan and ${ }^{2}$ Department of Surgical Pathology, Kumamoto University Hospital, 1-1-1 Honjo, Chuo-ku, Kumamoto 806-8556, Japan

Background: Oestrogens usually stimulate the progression of oestrogen receptor (ER)-positive breast cancer. Paradoxically, high-dose oestrogens suppress the growth of these tumours in certain circumstances.

Methods: We prospectively examined the efficacy and safety of ethinylestradiol treatment ( $3 \mathrm{mg}$ per day oral) in postmenopausal patients with advanced or recurrent ER-positive breast cancer who had previously received endocrine therapies, especially those with resistance to aromatase inhibitors.

Results: Eighteen patients were enrolled with the median age of 63 years and the mean observation time of 9.2 months. Three cases withdrew within 1 week due to oestrogen flare reactions with nausea, fatigue and muscle-skeletal pain. The response rate was $50 \%$ (9 out of 18), and the clinical benefit rate was $56 \%$ (10 out of 18). The stable disease ( $<6$ months) was $17 \%$ ( 3 out of 18 ) and another 2 cases were judged as progressive disease. Time-to-treatment failure including 2 on treatment was a median of 5.6 months (range 0.1 to $14.5^{+}$). Although vaginal bleeding or endometrial thickening was observed in patients receiving long-term treatment, there were no severe adverse events, such as deep venous thrombosis or other malignancies.

Conclusion: Although the mechanism of this treatment has not been fully understood, our data may contribute to change the common view of late-stage endocrine therapy.

The goal of treatment for metastatic breast cancer $(\mathrm{mBC})$ is to maintain the quality of life (QOL) and prolong survival of patients. Recently, the third-generation aromatase inhibitors (AI), such as anastrozole, letrozole and exemestane, have been mainly employed as an adjuvant therapy or an early recurrent treatment for postmenopausal breast cancer (Iwase, 2008). When AI treatment fails, it is unclear which endocrine therapy is the most appropriate. Options include selective oestrogen receptor modulators (SERMs) and fulvestrant, a selective ER downregulator (SERD). The hormone additive therapies, such as progestins (medroxyprogesterone acetate), androgen (fluoxymesterone), and oestrogen (ethinylestradiol; EE2) have also been advocated as endocrine therapies for $\mathrm{mBC}$ (Carlson et al, 2012).

Oestrogen usually stimulates the progression of ER-positive breast cancer. Paradoxically, high-dose oestrogens (HDE) suppress breast cancer growth in certain circumstances, particularly after 
long-term oestrogen depletion. Recently, Ellis et al (2009) reported a phase 2 randomized trial in postmenopausal women with hormone receptor-positive, AI-resistant advanced disease, comparing $30 \mathrm{mg}$ estradiol (E2, $10 \mathrm{mg}$, ter in die (TID)) with $6 \mathrm{mg}$ (2 mg, TID) to specifically address whether exposure to third-generation AI treatment sensitises advanced ER-positive breast cancer to lower, better tolerated, and safer doses of oestrogen. They concluded that a daily dose of $6 \mathrm{mg}$ E2 provided a clinical benefit rate (CBR) similar to that of $30 \mathrm{mg}$, with fewer serious adverse events.

Although EE2 (Prosexol) was approved in Japan in the 1970s for late-stage $\mathrm{mBC}$, no precise clinical data is available. To determine the efficacy and safety of EE2, especially after resistance to prior AIs, we attempted a prospective observational study using $3 \mathrm{mg}$ daily EE2 for postmenopausal patients with heavily pre-treated $\mathrm{mBC}$.

\section{PATIENTS AND METHODS}

Design. This trial was approved by the institutional review board of Kumamoto University Hospital and registered to the university hospital medical information network (UMIN) centre (UMIN000002831). Eligible patients had received prior treatment with an AI and heavily pre-treated by sequential endocrine therapies including chemotherapies for $\mathrm{mBC}$. Menopause status was defined as age $\geqslant 50$ years and amenorrhoea for 1 year or serum follicle-stimulating hormone (FSH) and E2 levels in the postmenopausal range before the prior AI therapy. Adequate haematological, renal, and hepatic function was required and treatment with bisphosphonate was adopted for all patients with bone metastasis. Ineligibility criteria were adopted if the case had other active malignancies and had a past history of deep venous thrombosis, stroke, ischaemic heart disease and endometrial disorder.

We initially conducted a phase 2 randomized trial in postmenopausal women with AI-resistant advanced disease to compare $6 \mathrm{mg}$ EE2 (2 mg, TID) and $3 \mathrm{mg}$ ( $1 \mathrm{mg}$, TID). In a pilot study of this trial, two of four cases treated with $3 \mathrm{mg}$ per day had response to the therapy, one had stable disease for 4 months, and one withdrew because of early oestrogen flare reactions with nausea, general fatigue, muscle-skeletal pain and slight fever. Upon consideration of these results, we changed the study design to determine the efficacy and safety of EE2 ( $3 \mathrm{mg}$ per day) as a prospective observational trial. Patients were included only after the trial had been explained to them, and they had given their written informed consent to join the trial.

The primary endpoint was CBR with secondary endpoints of safety, objective response rate (ORR) and time-to-treatment failure (TTF), which is the duration of treatment (in months) of patients who have failed on treatment including those with adverse events and also including patients still on treatment. The interim data was analysed because of the extremely beneficial results described as below. Moreover, when the patients felt any intolerable adverse effects after decreasing the daily dosage of EE2 to $2.0 \mathrm{mg}$ or $1.5 \mathrm{mg}$, the treatment was stopped. Additionally, $3 \mathrm{mg}$ per day EE2 was regarded as high dose, because when EE2 was used for avoiding the menopausal and postmenopausal symptoms, $10-50 \mu$ g orally per day was usually sufficient.

Patients. The characteristics of patients treated by $3 \mathrm{mg}$ per day EE2 are demonstrated in Table 1. Eighteen postmenopausal breast cancer patients with heavily pre-treated $\mathrm{mBC}$ were registered from October 2010 to January 2012. We evaluated the data at a mean observation time of 9.1 months. The patients' median age of EE2 treatment was 63 (range; 56-83) years. Four cases had primary advanced tumour (stage IV). All of the patients had been heavily treated in the advanced setting by a median of four prior endocrine therapies (range 2-7) and 10 of the 18 (56\%) had received a median of three prior chemotherapies (range 1-4). Prior endocrine treatement consisted of non-steroidal AIs in 13 cases (72\%) (letrozole in 7 and anastrozole in 6) or steroidal AIs in four cases (22\%), and exemestane with everolimus in one case (Table 1).

Oestrogen receptor (ER), progesterone receptor (PgR), and human epidermal growth factor receptor 2 (HER2) were estimated mainly by immunohistochemical assays using monoclonal antibodies against ER (SP1; Ventana Japan, Tokyo, Japan), PgR (1E2; Ventana, Japan) and Her2 (1:200; Dako, Tokyo, Japan); staining was carried out in a NexES IHC immunostainer (Ventana Medical Systems, Tucson, AZ, USA) (Yamamoto-Ibusuki et al, 2013). The status of ER and PgR was evaluated based on the percentage of positively stained nuclei. HER2 was evaluated using the HercepTest method (Dako) in accordance with ASCO-CAP (Vergara-Lluri et al, 2012). In several cases we were not able to analyse the receptor status in our laboratory because of long preservation time or missing samples.

Endpoints and methods of evaluation. Baseline evaluation included physical examination, blood and biochemical examination, blood coagulation and fibrinolysis examination (APTT, $\mathrm{D}$-dimer), and assays of E2 and FSH in serum. In general, bone scans, and computed tomography or positron emission tomography scans of the chest, abdomen, and pelvis were performed at base-line. Patients were evaluated at 4 -week intervals by physical examination and blood work similar to baseline.

The tumour reduction effect was evaluated in accordance with the Response Evaluation Criteria in Solid Tumors (RECIST) (Eisenhauer et al, 2009) at 8- or 12-week intervals or earlier if symptoms warranted. A complete response (CR) was defined as the complete disappearance of the measurable lesions; a partial response $(\mathrm{PR})$ as a decrease by $\geqslant 30 \%$ in the sum of the longest diameters (LDs) of measurable lesions; progressive disease (PD) as an increase of $20 \%$ or more in the sum of the LDs of measurable lesions; and long-lasting stable disease (long SD) as no change $(\mathrm{NC})$ in the size of measurable lesions for $\geqslant 24$ weeks. The objective response rate (ORR) was defined as the sum of the frequencies of $\mathrm{CR}$ and $\mathrm{PR}$, and the $\mathrm{CBR}$ as the sum of the frequencies of $\mathrm{CR}, \mathrm{PR}$ and long SD. Patients with only bone metastasis were included in the progression analysis by measuring changes in serum tumour markers, such as CEA and CA15-3. Specifically, reduction in tumour markers and complete calcification, with improvement of bone symptoms were judged to be PR. Additionally, serum levels of E2 and FSH were measured by enzyme immunoassay before treatment and after 4 weeks of administration. Adverse events were evaluated using the National Cancer Institute Common Toxicity Criteria, Version 4 (2009). Efficacy were independently reviewed and judged by the clinical trial office, Kumamoto University.

\section{RESULTS}

Efficacy of EE2 treatment. The efficacy results are shown in Table 2. Three of the 18 cases withdrew from EE2 administration within a few days because of their early oestrogen flare reactions, such as muscle skeletal pain, nausea, general fatigue and fever. Nine cases were evaluated as PR, one case as long SD, three cases as $\mathrm{SD}$, and another two cases as PD. Altogether, the ORR was 50\% (9 out of 18) and the CBR was 56\% (10 out of 18) in intention-totreat (ITT) analysis. Time-to-treatment failure in the ITT cohort $(n=18)$ including two ongoing cases was a median of 5.6 months (range $0.1-14.5^{+}$). Additionally, TTF in the 10 'experiencing clinical benefit' including 2 ongoing cases was a median of 8.2 months (range $5.4-14.5^{+}$) (Figure 1). Seven of the 10 cases 


\begin{tabular}{|c|c|c|c|c|c|c|c|c|c|c|}
\hline No & $\begin{array}{l}\text { Age of EE2 } \\
\text { treat-ment }\end{array}$ & $\begin{array}{c}\text { DFI } \\
\text { (year) }\end{array}$ & Sites of disease & $\begin{array}{l}\text { Previous therapies } \\
\text { for metastasis }\end{array}$ & $\begin{array}{l}\text { Best } \\
\text { response } \\
\text { prior ET }\end{array}$ & $\begin{array}{l}\text { \% of ER- } \\
\text { positive } \\
\text { cells }\end{array}$ & $\begin{array}{l}\% \text { of PgR- } \\
\text { positive } \\
\text { cells }\end{array}$ & $\begin{array}{l}\text { HER2- } \\
\text { IHC }\end{array}$ & $\begin{array}{l}\text { Best } \\
\text { response } \\
\text { of EE2 }\end{array}$ & $\begin{array}{c}\text { TTF } \\
\text { (months) }\end{array}$ \\
\hline 1 & 70 & 6.1 & Local, lung & E, A, Tor, L & $P R$ & $(+)$ & $(+)$ & $(-)$ & PR & 12.6 \\
\hline 2 & 70 & 10.0 & Bone, lung, liver & L, E + everolimus & Long SD & 95 & 20 & $2+$ & PR & 5.4 \\
\hline 3 & 79 & 6.0 & Bone, pleura & $\begin{array}{c}\text { Tam, A, MPA, E, L, S-1, } \\
\text { PTX, Tor, VNR, A }\end{array}$ & PR & 95 & 80 & $2+$ & PR & 8.2 \\
\hline 4 & 59 & 4.6 & Liver, local & $\begin{array}{c}\text { LHRHa + Tam, } \\
\text { LHRHa }+ \text { A, L, S-1, } \\
\text { VNR, PTX, E }\end{array}$ & PR & 95 & 5 & $1+$ & PR & 14.0 \\
\hline 5 & 62 & 4.3 & $\begin{array}{l}\text { Skin, Sc LN } \\
\text { (supraclavicular } \\
\text { lymph node) }\end{array}$ & E, EC, DTX, XC, L & Long SD & 90 & 0 & $1+$ & PR & 14.5 \\
\hline 6 & 64 & 5.9 & $\begin{array}{c}\text { Soft tissue, Cervical } \\
\text { LN }\end{array}$ & E, M, Tam, L, S-1, A & PD & 95 & 50 & 0 & PR & 11.9 \\
\hline 7 & 61 & 3.3 & Soft tissue, pleura & $\begin{array}{c}\text { Ta, E, A, MPA, Tor, } \\
\text { S-1, wPTX, L }\end{array}$ & Long SD & $(+)$ & $(+)$ & $(-)$ & PR & 7.0 \\
\hline 8 & 58 & Primary & Soft tissue, bone & AC, L, Tor, PTX, L & SD & 90 & 0 & $1+$ & PR & 7.7 \\
\hline 9 & 83 & Primary & $\begin{array}{l}\text { Locally advanced, } \\
\text { skin, soft tissue }\end{array}$ & $\begin{array}{l}\text { L, A, X, S-1, Tor, } \\
\text { WPTX, A }\end{array}$ & PD & 95 & 95 & $1+$ & PR & $8.2^{+}$ \\
\hline 10 & 61 & 8.7 & $\begin{array}{l}\text { Lung, pleura, soft } \\
\text { tissue }\end{array}$ & Tam, L, E & Long SD & $(+)$ & $(+)$ & $(-)$ & Long SD & $5.8^{+}$ \\
\hline 11 & 78 & 12.8 & Local, bone & L, E, Tam, Tor, A & PD & $(+)$ & $(+)$ & (uk) & SD & 3.5 \\
\hline 12 & 58 & 2.2 & Lung & A, E, Tor, L & Long SD & (90) & (30) & $(2+)$ & SD & 4.0 \\
\hline 13 & 56 & Primary & Liver, Lung & $A C, X T, A, E$ & PD & 90 & 5 & $1+$ & SD & 3.0 \\
\hline 14 & 72 & Primary & $\begin{array}{l}\text { Local, bone, soft } \\
\text { tissue }\end{array}$ & E, FUL, L, Tor, A & Long SD & 80 & 40 & $2+$ & PD & 3.0 \\
\hline 15 & 51 & 1.1 & Liver, Ax LN & $\begin{array}{c}\text { A, E, Tor, wPTX, DTX, } \\
\text { GEM + PTX, M, } \\
\text { EPIR, A, }\end{array}$ & SD & 95 & 0 & $2+$ & PD & 4.4 \\
\hline 16 & 59 & 3.7 & Sc LN & L, wPTX, X, EC, Tam, A & PD & $(+)$ & (uk) & (uk) & N/E & - \\
\hline 17 & 83 & 5.7 & Sc LN & $A, E, L$ & Long SD & $(+)$ & $(+)$ & (0) & $\mathrm{N} / \mathrm{E}$ & - \\
\hline 18 & 63 & 1.9 & Local, liver, bone & FUL, L, XT, Tor, E & PD & 80 & 5 & $2+$ & N/E & - \\
\hline
\end{tabular}

Table 2. Efficacy of ethinylestradiol

\begin{tabular}{|l|c|c|}
\hline Efficacy & $\begin{array}{c}\text { Number of } \\
\text { patients }\end{array}$ & $\begin{array}{c}\text { Intention-to-treat } \\
\text { cases (\%) (n= 18) }\end{array}$ \\
\hline Complete response & 0 & 0 \\
\hline Partial response & 9 & 50 \\
\hline Long stable disease & 1 & 5 \\
\hline Clinical benefit rate & 10 & 17 \\
\hline Stable disease & 3 & 11 \\
\hline Progressive disease & 2 & 17 \\
\hline $\begin{array}{l}\text { Withdrew cases in a } \\
\text { week }\end{array}$ & 3 & \\
\hline
\end{tabular}

experiencing clinical benefit had responded to prior endocrine therapy, whereas only 2 of the 5 cases 'non-experiencing clinical benefit' had responded to it.
ER, PgR, and HER2 expression levels in the biopsy samples. All of the cases had ER-positive tumours in primary and/or metastatic sites as shown in Table 1 . In 10 of the 18 cases, the expression of $\mathrm{ER}$ and $\mathrm{PgR}$ in the metastatic site prior to EE2 treatment was evaluated by IHC. Oestrogen receptor expression levels were high, with $80-95 \%$ positive staining in the tumour cells, but there were no differences in expression between patients who responded to EE2 treatment and those who did not. The expression of PgR varied from $0 \%$ to $95 \%$, with no relation to EE2 response. All 10 cases were HER2-negative.

In addition, ER and PgR expression levels were measured in five biopsy samples from among the above 10 cases during or after EE2 treatment. The ER levels tended to decrease, whereas the PgR levels tended to increase, although due to intratumoral heterogeneity the changes were not statistically significant (data not shown).

Serum levels of E2 and FSH. Serum E2 was elevated from the beginning level of $12 \pm 3 \mathrm{pg} \mathrm{ml}^{-1}$ (mean \pm standard deviation (s.d.)) to $43 \pm 27 \mathrm{pg} \mathrm{ml}^{-4}$ weeks later, and serum FSH was suppressed from the beginning level of $55 \pm 20 \mathrm{mIU} \mathrm{ml}^{-1}$ 
(mean \pm s.d.) to below premenopausal levels after 4 weeks of treatment (Figure 2). There was no correlation between hormone levels and response to treatment. Subsequent measurements of E2 and FSH levels at 4-6 week intervals showed no significant further changes during the course of treatment.

Adverse events. Acute symptoms of EE2 toxicity, such as nausea, general fatigue, muscle-skeletal pain, fever, headache, and occasionally vaginal bleeding, were seen in almost all the patients, but they were mostly mild and self-limiting (Table 3). Three patients withdrew from this trial due to oestrogen-flare reactions, such as nausea, fatigue and muscle-skeletal pain. Although signs of chronic toxicity, such as nipple/areola pigmentation, weight gain, irregular vaginal bleeding, or endometrial thickening, were observed in patients who received long-term treatment, there were no severe adverse events such as stroke, myocardial infarction, deep venous thrombosis or other malignancies in our trial. Especially, endometrial thickening and cervical cysts were frequently observed, but no patients displayed malignant features in the endometrium. Other adverse oestrogen-related symptoms such as jaundice, hypertension, nasal congestion, dizziness and

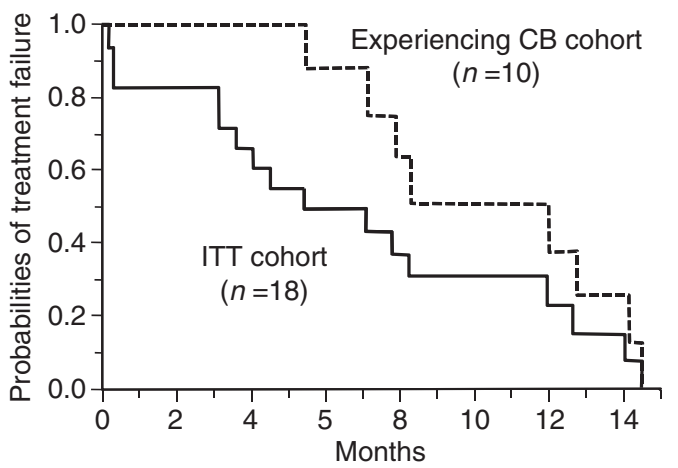

Figure 1. Kaplan-Meier curves of TTF. In the ITT cohort including two ongoing cases (solid line; $n=18$ ), the median TTP was 5.6 months (range 0.1 to $14.5^{+}$). In the 'experiencing clinical benefit' including two ongoing cases (dashed line; $n=10$ ), the median TTP was 8.2 months (range, $5.4-14.5^{+}$). fluid retention were not seen. None of the patients developed other malignancies.

\section{DISCUSSION}

Haddow et al (1944) published 'Influence of systemic oestrogen upon advanced malignant disease', in which 5 cases of 14 treated with diethylstilbestrol (DES) showed clinical response, whereas paradoxically, DES stimulated growth of the tumours in several other cases.

Table 3. Safety of EE2 treatment who were treated by ethinylestadiol $(n=18)$

\begin{tabular}{|l|c|c|c|c|}
\hline Safety & $\begin{array}{c}\text { All } \\
\text { grade } \\
(\boldsymbol{n}=\mathbf{1 8})\end{array}$ & $\begin{array}{c}\text { Grade } \\
\mathbf{1}\end{array}$ & $\begin{array}{c}\text { Grade } \\
\mathbf{2}\end{array}$ & $\begin{array}{c}\text { Grade } \\
\mathbf{3 , 4}\end{array}$ \\
\hline Nausea and vomiting & 14 & 7 & $\mathbf{7}^{\mathbf{a}}$ & 0 \\
\hline Muscle-skeletal pain & 10 & 7 & $3^{\text {a }}$ & 0 \\
\hline Fatigue & 10 & 7 & $3^{\text {a }}$ & 0 \\
\hline Hot flushes & 7 & 7 & 0 & 0 \\
\hline Fever & 5 & $5^{\text {a }}$ & 0 & 0 \\
\hline Liver dysfunction & 1 & 2 & 0 & 0 \\
\hline $\begin{array}{l}\text { Nipple/areola } \\
\text { pigmentation }\end{array}$ & 13 & 13 & 0 & - \\
\hline $\begin{array}{l}\text { Vaginal discharge/ } \\
\text { bleeding }\end{array}$ & 9 & 4 & 5 & - \\
\hline $\begin{array}{l}\text { Endometrial thickening } \\
\text { or uterocervical } \\
\text { enormousness }\end{array}$ & 13 & 13 & 0 & - \\
\hline Weight gain & 4 & 3 & 1 & 0 \\
\hline $\begin{array}{l}\text { Deep venous } \\
\text { thrombosis }\end{array}$ & 0 & 0 & 0 & 0 \\
\hline 2nd malignancy & 0 & 0 & 0 & 0 \\
\hline $\begin{array}{l}\text { a Three cases withdrew within 1 week with their early endocrine-related symptoms, such as } \\
\text { nausea, general fatigue, muscle-skeletal pain, and fever. }\end{array}$ & & \\
\hline
\end{tabular}

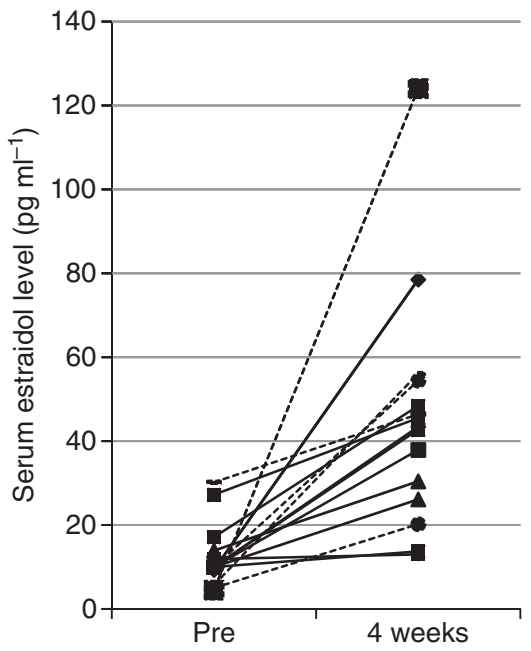

Figure 2. Serum level of E2 and FSH before treatment and 4 weeks later. Serum oestrogen was elevated from the beginning level of $12 \pm 3 \mathrm{pg} \mathrm{ml}^{-1}$ (mean \pm s.d.) to $45 \pm 12 \mathrm{pg} \mathrm{ml}^{-1} 4$ weeks later. Serum FSH was suppressed from the beginning level of $55 \pm 20 \mathrm{mlU} \mathrm{ml}^{-1}$ (mean \pm s.d.) to below premenopausal levels after 4 weeks of treatment. Solid lines indicate the 'experiencing clinical benefit' $(n=10)$, and dashed lines 'non-experiencing clinical benefit' $(n=5)$. 
Several studies have suggested the equivalent efficacy of tamoxifen and oestrogen therapy. Cole et al (1971) reported that tamoxifen had similar efficacy compared with DES in post-menopausal women with advanced breast cancer. Beex et al (1981) reported that objective remission due to EE2 was similar to that from tamoxifen ( $31 \%$ vs 33\%) in a randomized study of 63 post-menopausal women with advanced breast cancer. Ingle et al (1981) reported that the response rate for DES (41\%) was similar to that for tamoxifen $(33 \%)(P=0.37)$. A recent update of this trial reported significant $(P=0.039)$ survival advantage for patients receiving DES over tamoxifen (median survival of 3.0 years $v s 2.4$ years) (Ingle, 2002). Therefore, most of the studies proved that there was no statistically significant difference between the efficacy of tamoxifen and HDE. As tamoxifen had a favourable side-effect profile, it was the preferred agent to oestrogens.

Recently, Lonning et al (2001) reported that high-dose DES (15 mg daily) after the development of resistance to AIs in women with heavily pretreated $\mathrm{mBC}$ was effective, with an ORR of $31 \%$ (10 out of 32 ) and a CBR of $38 \%$ (12 out of 32 ), over a median duration of 50 weeks (range, $30-124^{+}$). Nineteen percent of patients ( 6 out of 32 ) discontinued treatment due to adverse events such as vaginal bleeding/discharge, nausea, diarrhoea, abdominal bloating, arthralgia, and dizziness. Agrawal et al (2006) reported a CBR of $33 \%$, median duration of response of 10 months (range, $7-36$ ), and TTF of 4 months (range, $0.5-36$ months) in 12 patients treated with HDEs. Mahtani et al (2009) reported an ORR of 25\% (5 out of 20 ) and CBR of $46 \%$ (12 out of 26) with a median duration of 10 months. Ellis et al (2009) reported a phase II randomized trial in postmenopausal women with HR-positive, AIresistant advanced disease comparing $30 \mathrm{mg}$ E2 with $6 \mathrm{mg}$. They concluded that E2 doses of $6 \mathrm{mg}$ per day provided a CBR similar to $30 \mathrm{mg}$ per day ( $29 \%$ (10 out of 34 ) vs $28 \%$ ( 9 out of 32 )), with fewer serious adverse events.

In our prospective study, an ORR of $50 \%$ ( 9 out of 18 ), and CBR of $56 \%$ (10 out of 18 ) with a median TTF of 35 weeks (range, $23-62^{+}$) can be interpreted as successful for a late-line endocrine therapy for $\mathrm{mBC}$, although $17 \%$ (3 out of 18) withdrew from the EE2 treatment after a few days. The reason for our results might be that all of the enrolled patients had a long history ( $>2$ years) of AI treatment or responded to AI therapy previously. This means the patients had 'acquired resistance' to oestrogen deprivation therapy using AIs.

The mechanisms by which HDEs suppress tumour growth are poorly understood. Several animal and in vitro studies provide insights into possible mechanisms by which tumours initially become resistant to endocrine therapy. Masamura et al (1995) found that depriving MCF-7 cells of oestrogen in tissue culture medium for periods of 1-6 months (long-term oestrogen deprivation; LTED) resulted in oestrogen hypersensitivity. These cells replicated at E2 concentrations of $10^{-15}-10^{-14} \mathrm{moll}^{-1}$, but the replication was inhibited at a concentration of $10^{-10}$. In contrast, wild-type MCF-7 cells replicated maximally at $10^{-10}$ moll $1^{-1}$ and required much higher doses for inhibition. Therefore, the authors found that the dose-response curve to oestrogen shifted to the left in the oestrogen-deprived cell line and hypothesised that the response observed to subsequent endocrine therapy was related to increased sensitivity to E2 (Santen et al, 2005).

In our study, ER expression levels were high, with $80-95 \%$ of positive staining in the tumour cells, which might show account for oestrogen hypersensitivity in the tumour cells, although there were no differences between responders and non-responders to EE2 treatment. The action of HDE in this condition may be resolved by applying molecular biological methods to re-biopsy samples.

Lewis et al (Lewis et al, 2005; Lewis-Wambi and Jordan, 2009) demonstrated the involvement of the extrinsic (Fas/FasL) and the intrinsic (mitochondria) pathways in oestrogen-induced apoptosis process. The NF-kappaB (nuclear factor-kappa-B)-mediated survival pathway as well as the PI3K (phosphoinositide 3-kinase)/Akt signalling pathway may also be involved. An oestrogen response element (ERE) has been identified in the promoter region of the FasL gene (Song et al, 2001). Therefore, physiologic levels of E2-induced regression of AI-resistant breast cancer tumours, apparently by inducing the death receptor Fas and suppressing the antiapoptotic/prosurvival factors NF-kappaB and HER2/neu. In our study, serum E2 concentration ranged $30-100 \mathrm{pg} \mathrm{ml}^{-1}$ which was thought to be within the physiologic levels in the premenopausal women.

Furthermore, Jordan et al (2009) propose that patients who have initially responded to, and then failed, two previous antihormonal therapies may exhibit 'Phase II antihormonal resistance'. These patients would benefit from short-term low-dose oestrogen, as oestrogen would induce apoptosis in the Phase II resistant cells and debulk the tumour. Their data indicate that the small percentage of Phase II tumours that revert to an oestrogen-stimulated stage after oestrogen-induced regression are also re-sensitised to antihormonal therapy. This suggests that AI or fulvestrant could be effective subsequent to EE2 treatment. Together, these data suggested that EE2 treatment should be used as a third-line therapy, especially in cases of acquired resistance to AIs.

EE2 also increases the water content of cervical mucus, favors contraction of the uterine myometrium, and blocks resorption of bone, resulting in a positive effect on bone mass. Control of the vasomotor symptoms associated with the perimenopausal period is thought to occur because of a blocking of the central nervous system outflow that regulates blood flow to cutaneous vessels. Oestrogen has a beneficial effect on plasma lipoprotein profiles, slightly elevating serum triglycerides, reducing serum cholesterol, increasing high-density lipoprotein levels and reducing low-density lipoprotein levels (Bennink, 2008). These various oestrogen effects cause several kinds of adverse events for the patients treated with EE2, but also some beneficial effects, such as improvement of vaginal dryness, skin dryness, and lipoprotein profiles.

We conclude that EE2 $3 \mathrm{mg}$ per day is beneficial for postmenopausal patients with $\mathrm{mBC}$ heavily pre-treated with endocrine therapies who could have acquired resistance to AIs, although attention to endocrine-related early and late adverse events is required.

\section{ACKNOWLEDGEMENTS}

This work was supported in part by a grant-in-aid (project numbers 2459191000) for scientific research from the Ministry of Education, Science and Culture of Japan. We wish to thank Ms Yuki Azakami for her excellent technical support.

CONFLICT OF INTEREST

The authors declare no conflict of interest.

\section{REFERENCES}

Agrawal A, Robertson JF, Cheung KL (2006) Efficacy and tolerability of high dose 'ethinylestradiol' in post-menopausal advanced breast cancer patients heavily pre-treated with endocrine agents. World J Surg Oncol 4: 44.

Beex L, Pieters G, Smals A, Koenders A, Benraad T, Kloppenborg P (1981) Tamoxifen versus ethinyl estradiol in the treatment of postmenopausal women with advanced breast cancer. Cancer Treat Rep 65: 179-185.

Bennink HJ (2008) Reprint of Are all estrogens the same? Maturitas 61: 195-201. Carlson RW, Allred DC, Anderson BO, Burstein HJ, Edge SB, Farrar WB, Forero A, Giordano SH, Goldstein LJ, Gradishar WJ, Hayes DF, Hudis CA, Isakoff SJ, Ljung BM, Mankoff DA, Marcom PK, Mayer IA, McCormick B, Pierce LJ, Reed EC, Smith ML, Soliman H, Somlo G, Theriault RL, Ward JH, Wolff AC, Zellars R, Kumar R, Shead DA (2012) 
Metastatic breast cancer, version 1.2012: featured updates to the NCCN guidelines. J Natl Compr Canc Netw 10: 821-829.

Cole MP, Jones CT, Todd ID (1971) A new anti-oestrogenic agent in late breast cancer. An early clinical appraisal of ICI46474. Br J Cancer 25: 270-275.

Eisenhauer EA, Therasse P, Bogaerts J, Schwartz LH, Sargent D, Ford R, Dancey J, Arbuck S, Gwyther S, Mooney M, Rubinstein L, Shankar L, Dodd L, Kaplan R, Lacombe D, Verweij J (2009) New response evaluation criteria in solid tumours: revised RECIST guideline (version 1.1). Eur J Cancer 45: 228-247.

Ellis MJ, Gao F, Dehdashti F, Jeffe DB, Marcom PK, Carey LA, Dickler MN, Silverman P, Fleming GF, Kommareddy A, Jamalabadi-Majidi S, Crowder R, Siegel BA (2009) Lower-dose $v s$ high-dose oral estradiol therapy of hormone receptor-positive, aromatase inhibitorresistant advanced breast cancer: a phase 2 randomized study. JAMA 302: 774-780.

Haddow A, Watkinson JM, Paterson E, Koller PC (1944) Influence of synthetic oestrogens on advanced malignant disease. Br Med J 2: 393-398.

Ingle JN (2002) Estrogen as therapy for breast cancer. Breast Cancer Res 4: 133-136.

Ingle JN, Ahmann DL, Green SJ, Edmonson JH, Bisel HF, Kvols LK, Nichols WC, Creagan ET, Hahn RG, Rubin J, Frytak S (1981) Randomized clinical trial of diethylstilbestrol versus tamoxifen in postmenopausal women with advanced breast cancer. N Engl J Med 304: 16-21.

Iwase H (2008) Current topics and perspectives on the use of aromatase inhibitors in the treatment of breast cancer. Breast Cancer 15: 278-290.

Jordan VC, Lewis-Wambi JS, Patel RR, Kim H, Ariazi EA (2009) New hypotheses and opportunities in endocrine therapy: amplification of oestrogen-induced apoptosis. Breast 18(Suppl 3): S10-S17.

Lewis JS, Osipo C, Meeke K, Jordan VC (2005) Estrogen-induced apoptosis in a breast cancer model resistant to long-term estrogen withdrawal. J Steroid Biochem Mol Biol 94: 131-141.

Lewis-Wambi JS, Jordan VC (2009) Estrogen regulation of apoptosis: how can one hormone stimulate and inhibit? Breast Cancer Res 11: 206.

Lonning PE, Taylor PD, Anker G, Iddon J, Wie L, Jorgensen LM, Mella O, Howell A (2001) High-dose estrogen treatment in postmenopausal breast cancer patients heavily exposed to endocrine therapy. Breast Cancer Res Treat 67: 111-116.

Mahtani RL, Stein A, Vogel CL (2009) High-dose estrogen as salvage hormonal therapy for highly refractory metastatic breast cancer: a retrospective chart review. Clin Ther 31(Pt 2): 2371-2378.

Masamura S, Santner SJ, Heitjan DF, Santen RJ (1995) Estrogen deprivation causes estradiol hypersensitivity in human breast cancer cells. J Clin Endocrinol Metab 80: 2918-2925.

National Cancer Institute (2009) Common Terminology Criteria for Adverse Events v.4.0 (CTCAE). Available at http://evs.nci.nih.gov/ftp1/CTCAE/ CTCAE_4.03_2010-06-14_QuickReference_5 × 7.pdf.

Santen RJ, Song RX, Zhang Z, Kumar R, Jeng MH, Masamura A, Lawrence Jr J, Berstein L, Yue W (2005) Long-term estradiol deprivation in breast cancer cells up-regulates growth factor signaling and enhances estrogen sensitivity. Endocr Relat Cancer 12(Suppl 1): S61-S73.

Song RX, Mor G, Naftolin F, McPherson RA, Song J, Zhang Z, Yue W, Wang J, Santen RJ (2001) Effect of long-term estrogen deprivation on apoptotic responses of breast cancer cells to 17beta-estradiol. J Natl Cancer Inst 93: 1714-1723.

Vergara-Lluri ME, Moatamed NA, Hong E, Apple SK (2012) High concordance between HercepTest immunohistochemistry and ERBB2 fluorescence in situ hybridization before and after implementation of American Society of Clinical Oncology/College of American Pathology 2007 guidelines. Mod Pathol 25: 1326-1332.

Yamamoto-Ibusuki M, Yamamoto Y, Yamamoto S, Fujiwara S, Fu P, Honda Y, Iyama K, Iwase H (2013) Comparison of prognostic values between combined immunohistochemical score of estrogen receptor, progesterone receptor, human epidermal growth factor receptor 2, Ki-67 and the corresponding gene expression score in breast cancer. Mod Pathol 26: 79-86.

This work is published under the standard license to publish agreement. After 12 months the work will become freely available and the license terms will switch to a Creative Commons AttributionNonCommercial-Share Alike 3.0 Unported License. 